\title{
Influence of Pectins on Preparation Characteristics of Lactoferrin Bioadhesive Tablets
}

\author{
Chikako Takeda, ${ }^{a}$ Yuri Takahashi, ${ }^{* a}{ }^{, a}$ Isamu Seto, ${ }^{b}$ Genji Kanano, ${ }^{b}$ Kozo TaKayama, ${ }^{c}$ \\ Hiraku ONISHI, ${ }^{a}$ and Yoshiharu MACHIDA ${ }^{a}$ \\ ${ }^{a}$ Department of Drug Delivery Research, Hoshi University; 2-4-41 Ebara, Shinagawa-ku, Tokyo 142-8501, Japan: ${ }^{b}$ NRL \\ Pharma, Inc.; 602 East Bldg. KSP, 3-2-1 Sakado, Takatsu-ku, Kawasaki 213-0012, Japan: and ${ }^{c}$ Department of \\ Pharmaceutics, Hoshi University; 2-4-41 Ebara, Shinagawa-ku, Tokyo 142-8501, Japan.
}

Received February 22, 2007; accepted May 12, 2007; published online May 14, 2007

For the treatment of chronic inflammation in the oral cavity, we attempted to develop bioadhesive tablets of bovine lactoferrin (B-LF). Pectin was used as a bioadhesive polymer, and the influence of the degree of esterification and the molecular weight of pectins on the characteristics of B-LF tablets were investigated. Concerning bioadhesive force, a tendency increasing the value according to increase of the esterification of the pectin was confirmed. Sustained release of B-LF from the tablets was observed as the esterification increased, and a possibility for prediction of the time required to release $50 \%$ of B-LF by using the equation given by the degree of esterification and the logarithm of the molecular weight was suggested. Pectin cross-linked with $\mathrm{Ca}^{2+}(\mathrm{Ca}-\mathrm{PC})$ was also used for the preparation of the B-LF tablets. Prolonged release of B-LF from the tablets was observed as the $\mathrm{Ca}^{2+}$ in $\mathrm{Ca}-\mathrm{PC}$ increased. Our findings suggest that pectin with a high degree of esterification is suitable as a bioadhesive polymer since high bioadhesive force and sustained release are shown. Furthermore, a possibility that the B-LF release could be controlled by adjusting the $\mathrm{Ca}^{2+}$ concentration in $\mathrm{Ca}-\mathrm{PC}$ was suggested.

Key words bioadhesive tablet; oral mucosa; pectin; lactoferrin

Chronic inflammation of the oral mucosa and gingiva is often observed accompanying intractable stomatitis. ${ }^{1)}$ The stomatitis reduces the quality of life of patients because it brings intense pain and anorexia. The severity and duration of stomatitis are greatly influenced by immune responses and oral hygiene condition. ${ }^{2}$ )

Lactoferrin, an iron-binding glycoprotein that consists of a single polypeptide chain, is an abundant protein in milk secretions. ${ }^{3)}$ Lactoferrin is found in most exocrine secretions including tears, nasal secretions, saliva, intestinal mucus and genital secretions, ${ }^{4,5}$ and is also identified as one of the major proteins present in neutrophils. ${ }^{6)}$ Lactoferrin shows its bactericidal effect by binding with iron ions that are essential for the growth of bacteria, ${ }^{7-9)}$ and also acts as a modulator for various immunologic functions. ${ }^{10)}$ The bactericidal effect and the immune regulatory function of lactoferrin should act to prevent the deterioration of stomatitis. Previously, we prepared buccal adhesive tablets consisting of bovine lactoferrin (B-LF), pectin and xylitol and evaluated the ulcer healing effect of the tablets by using rats induced with buccal mucosal ulcer. From the results, the ulcer decreased significantly at the seventh day in the group treated with the B-LF tablets as compared with the untreated group. (The in vivo data was presented on the 125th annual meeting of the Pharmaceutical Society of Japan, 2005).

Pectins are ionic plant polysaccharides that are widely used in the food industry for their gelling properties. Their main structural features consist of blocks of $(1 \rightarrow 4)$-linked homogalacturonan interrupted by single $(1 \rightarrow 2)$-linked rhamnose units. ${ }^{11-13)}$ The homogalacturonan blocks are copolymers of galacturonic acid and its methyl ester, and the degree of esterification characterizes the gelation of pectins. Fifty $\%$ or more of the carboxyl groups are methyl esterified in native pectins. They are categorized as highly methylated pectins (HM pectins). Pectins of lower ester content (LM pectins) can be prepared by controlled acid deesterification. ${ }^{14)}$ As shown in Fig. 1, LM pectins readily form gels in aqueous solution by cross-linking with free $\mathrm{Ca}^{2+} \cdot{ }^{15-18)}$

In this study, we attempted to investigate the influence of the degree of esterification and the molecular weight of pectins on the characteristics of B-LF bioadhesive tablets, because preparation characteristics such as bioadhesive force and B-LF release properties may influence the ulcer healing effect. Pectins of various degrees of esterification and LM pectins cross-linked with $\mathrm{Ca}^{2+}$ were used to prepare B-LF bioadhesive tablets, and the usefulness of the pectins as a bioadhesive polymer were evaluated.

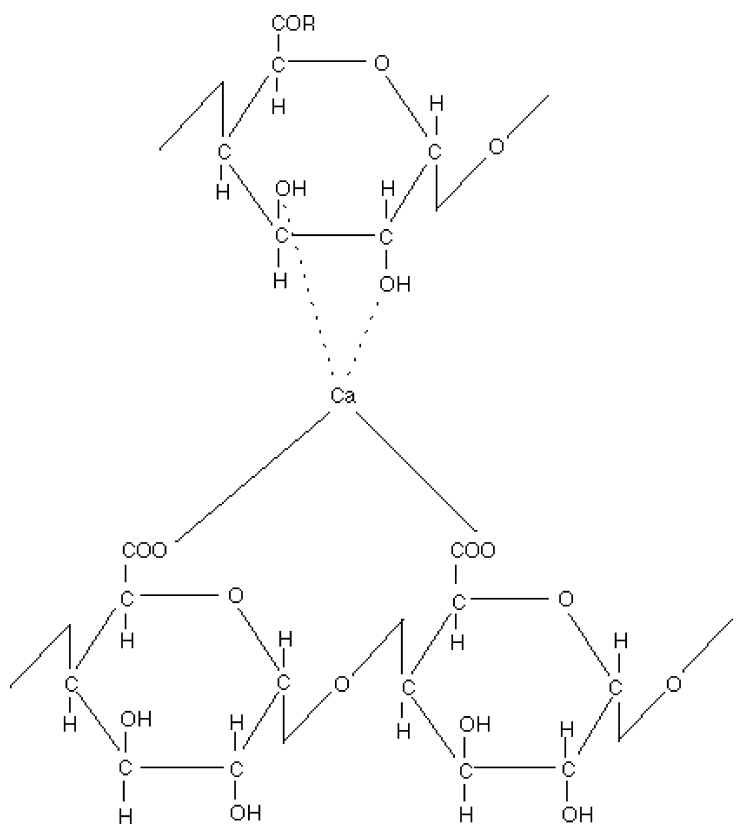

Fig. 1. Structure of Pectin Cross-Linked with $\mathrm{Ca}$ 


\section{Experimental}

Materials B-LF was supplied by NRL Pharma, Inc. (Kanagawa, Japan). Pectin B was purchased from Happou Syoukai Co., Ltd. (Tokyo, Japan) GENU pectin type BB rapid set-j (pectin A), GENU pectin type AS Confectionery-J (pectin C) and GENU pectin type LM-101AS-JS-J (pectin D) were supplied by Sansho Co., Ltd. (Osaka, Japan). Xylitol was purchased from Wako Pure Chemical Industries, Ltd. (Osaka, Japan). All other chemicals were obtained commercially at the purest grade available.

Animals Male ddY strain mice weighing 25-30g were purchased from Tokyo Laboratory Animals Science Co., Ltd. (Tokyo, Japan). The experimental protocol was approved by the Ethics Review Committee for Animal Experimentation of Hoshi University. The guideline for animal experimentation of Hoshi University conforms to the basic guideline made by the Ministry of Education, Culture, Sports, Science and Technology of Japan.

Purification and Characterization of Pectins The characteristics of the pectins used in this study are shown in Table 1. Commercially available pectins contain sucrose to maintain product quality, so purification of pectins was performed to remove the sucrose. Pectins were dissolved in purified water and adjusted to $\mathrm{pH} 3.8$ by addition of aqueous sodium hydrate $(1 \mathrm{~mol} / \mathrm{l})$ for stabilization of the pectins. ${ }^{13)}$ Ethanol (99.5\%) was gradually poured into the pectin solution and the precipitate was separated by a glass filter. The pectin precipitate was washed by ethanol and dried for $3 \mathrm{~h}$ at $60{ }^{\circ} \mathrm{C}$ in the presence of $\mathrm{P}_{2} \mathrm{O}_{5}$, for $12 \mathrm{~h}$ at room temperature, and finally for $3 \mathrm{~h}$ at $100^{\circ} \mathrm{C}$ under reduced pressure.

The measurement of molecular weight was performed using a pump ( $\mathrm{Ag}$ ilenp 1100 series) connected to a multiangle light scattering (MALS) detector set at $690 \mathrm{~nm}$ (DAWN EOS, Wyatt Technology, CA, U.S.A.) and a differential refractometer detector (Optilab rEX, Wyatt Technology). The viscosity of pectin solutions $(0.7 \%, \mathrm{w} / \mathrm{v})$ was measured using a rotational viscometer (TVB-10M, Toki Sangyo Co., LTD., Tokyo, Japan). Acetate buffer solution $(0.1 \mathrm{~mol} / 1, \mathrm{pH} 3.4)$ was used as a solvent. The viscosity of pectin solutions $(0.7 \%, \mathrm{w} / \mathrm{v})$ added calcium chlorite was also measured. Pectins were dissolved in acetate buffer solution $(0.1 \mathrm{~mol} / 1, \mathrm{pH} 3.4)$, and calcium chlorite of $0.5,1.0,1.5$ and $2.0 \%(\mathrm{w} / \mathrm{w})$ to the amount of the pectin was added. The measurement was performed at $5 \pm 1{ }^{\circ} \mathrm{C}$.

Preparation of B-LF Tablets B-LF tablets consisting of B-LF $(25 \mathrm{mg})$, pectin $(25 \mathrm{mg})$ and xylitol $(15 \mathrm{mg})$ were prepared by direct compression at a force of $10 \mathrm{kN}$ using a hydraulic hand press (Shimadzu Co., Kyoto, Japan). All the ingredients were passed through a 100 mesh sieve after grinding in an agate mortar using a pestle. The B-LF tablets were prepared as a plate tablet with a diameter of $8 \mathrm{~mm}$. Pectin $\mathrm{D}$, which had the lowest degree of esterification, was used for cross-linking with $\mathrm{Ca}^{2+}$, and B-LF tablets containing the pectin cross-linked with $\mathrm{Ca}^{2+}(\mathrm{Ca}-\mathrm{PC})$ were also prepared. Pectin $\mathrm{D}$ was dissolved in purified water, and calcium chlorite of $0.5,1.0$ and $1.5 \%$ $(\mathrm{w} / \mathrm{w})$ to the amount of the pectin was added. After adequate agitation, ethanol $(99.5 \%)$ was poured gradually into the solution and the precipitate of $\mathrm{Ca}-\mathrm{PC}$ was separated by a glass filter. The $\mathrm{Ca}-\mathrm{PC}$ was washed and dried in the same manner of purification as for pectins, and then used for preparation of the B-LF tablets.

Measurement of Characteristics of B-LF Tablets Tensile Strength: The thickness and the diameter of the tablets were determined using a vernier caliper. The hardness of the tablets was determined by a KIYA Hardness Tester (Fujiwara Scientific Company Co., Ltd., Japan). The tablet tensile strength $(T)$ was calculated using the following equation, ${ }^{19}$ )

$$
T=2 F / \pi d t
$$

where $F, d$ and $t$ denote the diametral crushing force, the tablet diameter and the tablet thickness, respectively.

Water Absorption Properties: Water absorption properties of the tablets were assessed according to the method reported by Nakamura et al. ${ }^{20)}$ In brief, a measuring pipette was filled with purified water and a scale brought to the starting point. The pipette was then connected to a tray consisting of a glass filter, and a tablet was put on the center of the tray. The distance of movement of the meniscus from the starting point for $30 \mathrm{~s}$ (volume of water absorbed, $\mu \mathrm{l}$ ) was measured, and the mean of water absorption rates at $5 \mathrm{~s}$ intervals from 0 to $20 \mathrm{~s}$ (water absorption rate, $\mu \mathrm{l} / \mathrm{s}$ ) was calculated.

Bioadhesive Force: The in vitro bioadhesive force of B-LF tablets was determined using a FUDOH Rheometer (Fudoh Kogyo Co., Ltd., Japan) by the modified method of Ishida et al. ${ }^{21)}$ After cerebral dislocation, a mouse peritoneal membrane was excised and mounted on an adapter (No. 3, diameter $10 \mathrm{~mm}$ ) with the mucosal side facing the outside. The membrane was rinsed with physiological saline before it was used, and any excess moisture was wiped off using a filter paper. A tablet was fastened to the tray of the rheometer using double-sided adhesive tape, and attached to the membrane with a force of $200 \mathrm{~g}$ for $30 \mathrm{~s}$. The tray was then lowered at a speed of $2 \mathrm{~cm} / \mathrm{min}$. The stress on the separation of the tablet from the membrane was measured.

Release Test: The release test was performed according to the Japanese Pharmacopoeia XIV paddle method in $250 \mathrm{ml}$ of $1 / 15 \mathrm{M}$ phosphate buffer $\left(\mathrm{pH} 6.8,37^{\circ} \mathrm{C}\right.$ ) with constant stirring at $60 \mathrm{rpm}$. A B-LF tablet was attached on a glass plate with $10 \mu \mathrm{l}$ of phosphate buffer and the glass plate was put into the dissolution medium in order to keep the tablet at the bottom. The dissolution medium $(0.5 \mathrm{ml})$ was sampled at predetermined times until the tablets disappeared and an equal volume of the buffer was added to compensate after each sampling. The B-LF released was measured using the BCA Protein Assay Reagent Kit (Pierce Biotechnology, Inc., IL, U.S.A.)

Multiple Regression Analysis Multiple regression analysis was performed to evaluate correlation between the physicochemical properties of pectins and the characteristics of B-LF tablet. ${ }^{22,23}$ Pectin D, which is the only amidated pectin, was excluded from the analysis. The degree of esterification of the pectins $\left(X_{1}, \%\right)$ and the logarithm of the molecular weight of the pectins $\left(X_{2}\right)$ were selected as causal factors. The bioadhesive force $\left(Y_{1}, \mathrm{~g}\right)$ and the time required to release $50 \%$ of B-LF $\left(Y_{2}, \min \right)$ were predicted by multiple regression analysis based on a first-order polynomial equation. The viscosity of the pectin solutions $\left(Z_{1}, \mathrm{mPa} \cdot \mathrm{s}\right)$, the tensile strength $\left(Z_{2}, \mathrm{MPa}\right)$ and the volume of water absorbed within $30 \mathrm{~s}\left(Z_{3}, \mu \mathrm{l}\right)$, which were regarded as intermediate preparation properties, were also predicted as response variables.

Statistical Analysis Variance in a group was evaluated by the $F$-test, and differences in water absorption properties were evaluated by Student's $t$-test. The data were considered to be significantly different when the $p$-value was less than 0.05 .

\section{Results and Discussion}

Characterization of Pectins The characteristics of pectins are shown in Table 1. From the measurement of the molecular weight, the lower molecular weight of pectin B than the others was confirmed. The degree of esterification listed is the data measured by manufacturers. The viscosity of the pectin solutions is shown in Table 1. From the results, increase of the viscosity according to increase of the degree of esterification was confirmed. However, the viscosity of pectin $B$, which had a relatively low molecular weight, was lower than that of the other pectins. The viscosity of pectin solutions with calcium chloride added is shown in Table 2. In all the pectins, increase of the viscosity according to increase

Table 1. Characteristics of Pectins

\begin{tabular}{cccccc}
\hline \hline Pectin & Type $^{a)}$ & $\begin{array}{c}\text { Molecular } \\
\text { weight }\end{array}$ & $\begin{array}{c}\text { Esterification } \\
(\%)\end{array}$ & $\begin{array}{c}\text { Amidation } \\
(\%)\end{array}$ & $\begin{array}{c}\text { Viscosity } \\
(\mathrm{mPa} \cdot \mathrm{s})\end{array}$ \\
\hline A & HM & $1.758 \times 10^{6}$ & 71 & - & $23.2 \pm 0.2$ \\
B & HM & $0.950 \times 10^{4}$ & 59.6 & - & $15.8 \pm 0.6$ \\
C & HM & $2.803 \times 10^{6}$ & 52 & - & $20.7 \pm 0.3$ \\
D & LM & $2.528 \times 10^{6}$ & 38 & 14 & $18.7 \pm 0.2$
\end{tabular}

a) HM: high methoxyl pectin, LM: low methoxyl pectin. b) Viscosity of pectin solutions $(0.7 \%, \mathrm{w} / \mathrm{v})$ was measured. Each value represents the mean \pm S.D. $(n=3)$.

Table 2. Viscosity $(\mathrm{mPa} \cdot \mathrm{s})$ of Pectin Solutions

\begin{tabular}{cccccc}
\hline \hline & \multicolumn{5}{c}{ Concentration of $\mathrm{CaCl}_{2}(\%)$} \\
\cline { 2 - 6 } Pectin & 0 & 0.5 & 1.0 & 1.5 & 2.0 \\
\hline A & $23.2 \pm 0.2$ & $23.4 \pm 0.1$ & $24.8 \pm 0.2$ & $25.7 \pm 0.4$ & $26.4 \pm 0.3$ \\
B & $15.8 \pm 0.6$ & $16.1 \pm 0.3$ & $18.8 \pm 0.5$ & $21.4 \pm 2.1$ & $22.3 \pm 1.3$ \\
C & $20.7 \pm 0.3$ & $21.7 \pm 0.7$ & $24.5 \pm 0.9$ & $25.9 \pm 0.2$ & $29.2 \pm 1.0$ \\
D & $18.7 \pm 0.2$ & $20.9 \pm 0.7$ & $26.4 \pm 1.2$ & $39.9 \pm 6.9$ & $77.0 \pm 10.8$
\end{tabular}

Each value represents the mean \pm S.D. $(n=3)$ 
Table 3. Characteristics of B-LF Tablets Containing Pectin A, B, C or D

\begin{tabular}{|c|c|c|c|c|}
\hline \multirow[b]{2}{*}{ Tablet } & \multirow[b]{2}{*}{ Tensile strength $^{a)}(\mathrm{MPa})$} & \multirow[b]{2}{*}{ Thickness $^{a)}(\mathrm{mm})$} & \multicolumn{2}{|c|}{ Water absorption properties ${ }^{b)}$} \\
\hline & & & $\begin{array}{l}\text { Volume of water absorbed } \\
\text { within } 30 \mathrm{~s}(\mu \mathrm{l})\end{array}$ & $\begin{array}{c}\text { Average water absorption rate } \\
\text { within } 20 \mathrm{~s}(\mu \mathrm{l} / \mathrm{s})\end{array}$ \\
\hline Pectin A & $4.14 \pm 0.54$ & $1.15 \pm 0.00$ & $5.00 \pm 1.00$ & $0.21 \pm 0.04$ \\
\hline Pectin B & $5.01 \pm 0.09$ & $1.16 \pm 0.03$ & $6.40 \pm 0.55$ & $0.30 \pm 0.04$ \\
\hline Pectin C & $3.18 \pm 0.28$ & $1.16 \pm 0.04$ & $7.20 \pm 0.45^{*}$ & $0.31 \pm 0.02$ \\
\hline Pectin D & $4.51 \pm 0.21$ & $1.19 \pm 0.02$ & $6.60 \pm 0.89$ & $0.30 \pm 0.04$ \\
\hline
\end{tabular}

a) Each value represents the mean \pm S.D. $(n=6) . \quad b)$ Each value represents the mean \pm S.D. $(n=5) . * p<0.05$ versus pectin B.

of $\mathrm{Ca}^{2+}$ was confirmed. Particularly, pectin D showed a high sensitivity to $\mathrm{Ca}^{2+}$, and the viscosity of the pectin $\mathrm{D}$ solution containing $2 \% \mathrm{CaCl}_{2}$ was fourfold that of the initial pectin $\mathrm{D}$ solution. Hence, in this study, pectin D was used for the preparation of $\mathrm{Ca}-\mathrm{PC}$ to investigate the preparation characteristics of B-LF tablets containing Ca-PC.

Effect of Pectins on the Characteristics of B-LF Tablets Tensile strength and thickness of B-LF tablets are shown in Table 3. The tablets containing pectin B showed the highest value of tensile strength. However, the values of all tablets were sufficiently high, and all the tablets could be applied to the buccal mucosa without collapse. Water absorption properties of B-LF tablets are shown in Table 3. Since hydration of the tablets should influence the bioadhesive property, the volume of water absorbed into the tablets was investigated. From the results, high water absorption properties in the tablets containing the low esterified pectin were confirmed. Bioadhesive force of B-LF tablets is shown in Fig. 2. Although the variation was large, increase of bioadhesive force according to increase of esterification of the pectins was confirmed. The five theories that are most commonly presented in conjunction with bioadhesion are the absorption, diffusion, electronic, fracture and wetting theories. ${ }^{24)}$ For dry dosage forms, wetting, hydration and swelling of the dosage form will initiate the intimate contact with the tissue. Secondly, there will be an interpenetration of the components, the polymers of the dosage form and the mucus gel network on the surface of the tissue, across the interface. The interpenetrated chains can then interact, resulting in entanglements and weak chemical bonds, originating from electrostatic attraction, hydrophobic interactions, van der Waals forces and hydrogen bonds. In this study, pectin A and B showed a relatively high bioadhesive force, whereas pectin $\mathrm{C}$ showed significantly higher water absorption properties as compared with pectin B. It is considered that the tablets with high water absorption properties gel by hydration and contact with the mucosa. Then, the polymer of the tablets and the mucus on the surface of the tissue can interpenetrate and interact by weak chemical bonds. Although a possibility that the viscosity of the pectins influenced bioadhesive force was considered, the viscosity of the pectin solutions was not proportional to bioadhesive force. Thus, as the reason that pectin $\mathrm{C}$ and $\mathrm{D}$ showed lower bioadhesive force, pectin $\mathrm{C}$ and $\mathrm{D}$ might carry a charge by wetting, and intramolecular and intermolecular electrical repulsion might be generated. In contrast, pectin A and B have weak electrical repulsion, and the interpenetration of the components between the tablets and the mucus gel network might develop efficiently. The release profiles of B-LF from bioadhesive tablets are shown

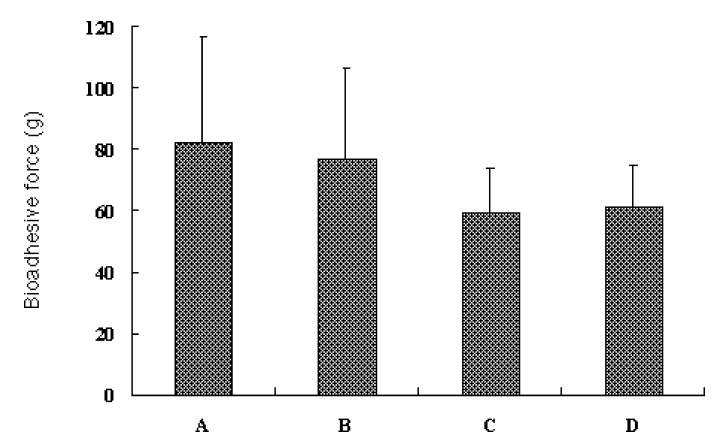

Fig. 2. Bioadhesive Force of B-LF Tablets Containing Pectin A, B, C or D Each value represents the mean \pm S.D. $(n=6)$.



Fig. 3. Release Profiles of B-LF from B-LF Tablets Containing Pectin A, $\mathrm{B}, \mathrm{C}$ or $\mathrm{D}$

Each point represents the mean \pm S.D. $(n=3)$.

in Fig. 3. The data were fitted by a curve of the second order. According to the increase of esterification, sustained release of B-LF was observed. The times required to release $50 \%$ of B-LF from B-LF tablets containing pectin A, B, C and D were $126.4,80.0,62.7$ and 45.8 min, respectively. B-LF is a glycoprotein of $80 \mathrm{kDa}$ molecular weight. Although B-LF could be released through the interval of the polymers, there was a possibility that B-LF was released as the polymer was dispersed. Pectin is dispersed in water by forming anionic hydrocolloid. ${ }^{13)}$ Since carboxyl groups of pectin dissociate at over pH 3.5, ${ }^{13)}$ LM pectin may disperse easily in the dissolution medium ( $\mathrm{pH}$ 6.8). Thus, it is considered that the dispersion of the pectins is one of the important factors to decide the release property in the B-LF tablets containing the pectins as a bioadhesive polymer.

Analysis of Preparation Characteristics The regression equations to predict the preparation characteristics are 
shown in Table 4. Although the bioadhesive force $\left(Y_{1}\right)$ was given by an equation interacted with the degree of esterification $\left(X_{1}\right)$ and the logarithm of the molecular weight $\left(X_{2}\right)$, the multiple correlation coefficient was low. As the reason for this, existence of a large variation in the data was considered. The time required to release $50 \%$ of B-LF $\left(Y_{2}\right)$ was also given by an equation interacted with $X_{1}$ and $X_{2}$, and the multiple correlation coefficient was sufficiently high. Hence, a possibility for prediction of $Y_{2}$ by using the equation given by $X_{1}$ and $X_{2}$ was suggested. In Fig. 4, three dimensional graphs of the regression equations are shown. The bioadhesive force $\left(Y_{1}\right)$ rose as the logarithm of the molecular weight decreased and as the degree of esterification increased. From the results, it is considered that HM pectin with low molecular weight easily interpenetrates to the mucus and shows high bioadhesive force. The time required to release $50 \%$ of B-LF $\left(Y_{2}\right)$ increased as the degree of esterification increased, and as the logarithm of the molecular weight increased at the area of

Table 4. Regression Equations for Prediction of Characteristics of B-LF Tablets

1) $Y_{n}=a X_{1}+b X_{2}+c X_{1} X_{2}+d$

\begin{tabular}{cccccc}
\hline \hline & $a$ & $b$ & $c$ & $d$ & $R$ \\
\hline$Y_{1}$ & - & $-14.34 \pm 21.00$ & $0.18 \pm 0.28$ & $90.21 \pm 69.67$ & 0.363 \\
$Y_{2}$ & - & $-28.32 \pm 7.62$ & $0.54 \pm 0.10$ & $66.74 \pm 25.28$ & 0.983
\end{tabular}

2) $Z_{\mathrm{n}}=a X_{1}+b X_{2}+c X_{1} X_{2}+d$

\begin{tabular}{rcrrrr}
\hline \hline & $a$ & \multicolumn{1}{c}{$b$} & $c$ & \multicolumn{1}{c}{$d$} & $R$ \\
\hline$Z_{1}$ & $0.16 \pm 0.04$ & $2.48 \pm 0.27$ & - & $-3.51 \pm 2.76$ & 0.995 \\
$Z_{2}$ & $0.04 \pm 0.03$ & $-0.61 \pm 0.17$ & - & $4.81 \pm 1.78$ & 0.904 \\
$Z_{3}$ & - & $1.05 \pm 0.61$ & $-0.02 \pm 0.01$ & $6.56 \pm 2.01$ & 0.821 \\
\hline
\end{tabular}

$X_{1}$ : degree of esterification of pectin (\%), $X_{2}$ : logarithm of molecular weight of pectin, $Y_{1}$ : bioadhesive force $(\mathrm{g}), Y_{2}$ : time required to release $50 \%$ of B-LF (min), $Z_{1}$ : viscosity of pectin solutions $(\mathrm{mPa} \cdot \mathrm{s}), Z_{2}$ : tensile strength $(\mathrm{MPa}), Z_{3}$ : volume of water absorbed within $30 \mathrm{~s}(\mu 1)$.

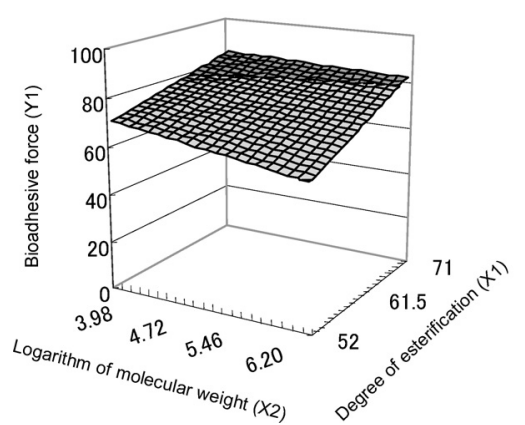

the high degree of esterification. The viscosity of the pectin solutions $\left(Z_{1}\right)$ and the tensile strength $\left(Z_{2}\right)$ were given by a first-order equation of $X_{1}$ and $X_{2}$. Namely, the viscosity of the pectin solutions $\left(Z_{1}\right)$ correlated with the degree of esterification and the logarithm of the molecular weight positively, and the tensile strength $\left(Z_{2}\right)$ correlated with the degree of esterification positively and with the logarithm of the molecular weight negatively. In this study, although we tried to find the correlation between the viscosity of the pectin solutions $\left(Z_{1}\right)$ and the bioadhesive force $\left(Y_{1}\right)$, it could not be successful because the viscosity of the pectin solutions was not proportional to bioadhesive force. The volume of water absorbed within $30 \mathrm{~s}\left(Z_{3}\right)$ was given by an equation interacting with $X_{1}$ and $X_{2}$, and the correlation was good. From these results, it is suggested that the characteristics of B-LF tablets except the bioadhesive force can be predicted by determining the degree of esterification and the logarithm of the molecular weight of pectins.

Characteristics of B-LF Tablets Containing Ca-PC Tensile strength and thickness of B-LF tablets containing Ca$\mathrm{PC}$ are shown in Table 5. As for tensile strength, a tendency to decrease was seen as the amount of $\mathrm{Ca}^{2+}$ increased. Although the particle size of Ca-PC did not change as compared with pectin $\mathrm{D}$, the bulk density of the particles was decreased. It was considered that the crystal form of pectin was transformed by cross-linking with $\mathrm{Ca}^{2+}$. In this study, since pectin $\mathrm{B}$ of low molecular weight showed the highest value of tensile strength, the cross-linked pectin might act as a high molecular weight pectin. Water absorption properties of $\mathrm{B}$ LF tablets containing Ca-PC are shown in Table 5. The CaPC tablets rapidly absorbed water while swelling as compared with the pectin D tablets. It is considered that Ca-PC has a good water absorption property. In the Ca-PC (1.5\%) tablets, the viscosity of the penetration water might be increased by dissolution of $\mathrm{Ca}-\mathrm{PC}$ and penetration to the upper side of the capillaries was inhibited. Bioadhesive force of B-

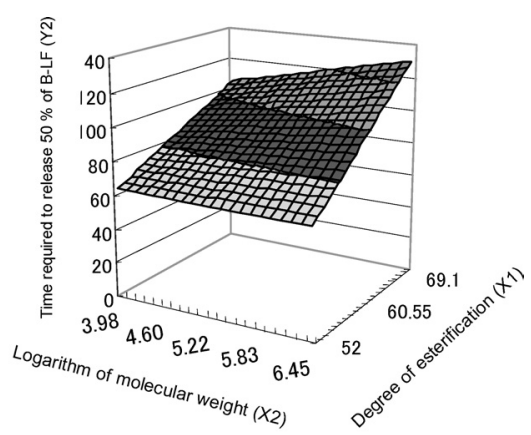

Fig. 4. Three Dimensional Graphs of Regression Equations Obtained by Multiple Regression Analysis

Table 5. Characteristics of B-LF Tablets Containing Ca-PC

Water absorption properties ${ }^{b)}$

\begin{tabular}{|c|c|c|c|c|}
\hline \multirow[b]{2}{*}{ Tablet } & \multirow[b]{2}{*}{ Tensile strength $^{a)}(\mathrm{MPa})$} & \multirow[b]{2}{*}{ Thickness $^{a)}(\mathrm{mm})$} & \multirow[b]{2}{*}{$\begin{array}{c}\text { Volume of water absorbed } \\
\text { within } 30 \mathrm{~s}(\mu \mathrm{l})\end{array}$} & \multirow[b]{2}{*}{$\begin{array}{l}\text { Average water absorption } \\
\text { rate within } 20 \mathrm{~s}(\mu \mathrm{l} / \mathrm{s})\end{array}$} \\
\hline & & & & \\
\hline Pectin D & $4.51 \pm 0.21$ & $1.19 \pm 0.02$ & $6.60 \pm 0.89$ & $0.30 \pm 0.04$ \\
\hline $\mathrm{Ca}-\mathrm{PC}(0.5 \%)$ & $4.39 \pm 0.22$ & $1.26 \pm 0.02$ & $7.80 \pm 1.92$ & $0.34 \pm 0.07$ \\
\hline Ca-PC $(1.0 \%)$ & $4.12 \pm 0.65$ & $1.20 \pm 0.03$ & $7.80 \pm 0.84$ & $0.36 \pm 0.05$ \\
\hline Ca-PC (1.5\%) & $3.08 \pm 0.46$ & $1.21 \pm 0.02$ & $7.20 \pm 1.30$ & $0.32 \pm 0.08$ \\
\hline
\end{tabular}

a) Each value represents the mean \pm S.D. $(n=6)$. b) Each value represents the mean \pm S.D. $(n=5)$. 


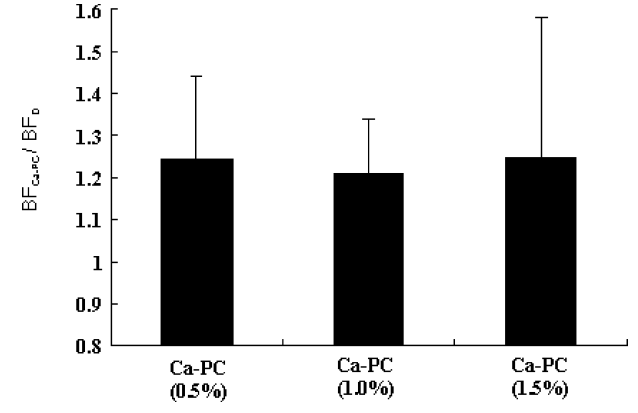

Fig. 5. Comparison of Bioadhesive Force of B-LF Tablets Containing Ca-PC $\mathrm{BF}_{\mathrm{D}}$ : bioadhesive force of $\mathrm{B}-\mathrm{LF}$ tablets containing pectin $\mathrm{D}, \mathrm{BF}_{\mathrm{Ca}-\mathrm{PC}}$ : bioadhesive force of B-LF tablets containing Ca-PC. Each value represents the mean \pm S.D. $(n=5)$

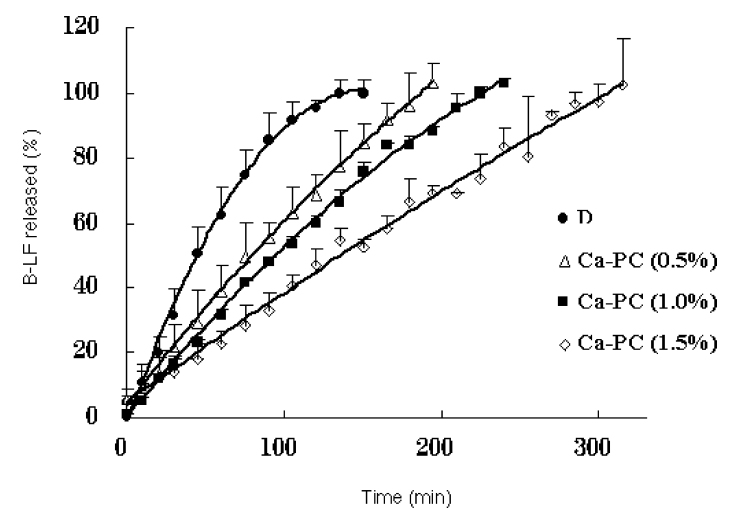

Fig. 6. Release Profiles of B-LF from B-LF Tablets Containing Ca-PC Each point represents the mean \pm S.D. $(n=3)$

LF tablets containing Ca-PC is shown in Fig. 5. The data are shown as the ratio of the value of the Ca-PC tablets to the value of the pectin $\mathrm{D}$ tablet. Although the bioadhesive force of the Ca-PC tablets tended to increase as compared with the pectin $\mathrm{D}$ tablets, the value did not rise as the amount of the $\mathrm{Ca}^{2+}$ addition increased. As shown in Fig. 1, pectin is crosslinked with $\mathrm{Ca}^{2+}$ using hydroxyl and free carboxyl groups. Since the preparations can adhere to the mucosa as a result of chemical bonds, such as hydrogen bonds, van der Waals forces and electrostatic attractions, the hydroxyl group of pectin may be used for adhesion. Hence, although the viscosity of the Ca-PC solutions increased as the amount of the $\mathrm{Ca}^{2+}$ addition increased, the bioadhesive force might not be improved according to the $\mathrm{Ca}^{2+}$ concentration. The release profiles of B-LF from bioadhesive tablets are shown in Fig. 6 . The times required to release $50 \%$ of B-LF from B-LF tablets containing Ca-PC (0.5), Ca-PC (1.0) and Ca-PC (1.5) were $80.1,94.2$ and $148.1 \mathrm{~min}$, respectively. Prolonged release of B-LF from the bioadhesive tablets was observed as the amount of the $\mathrm{Ca}^{2+}$ addition increased. From the result, the $\mathrm{B}-\mathrm{LF}$ release from the $\mathrm{Ca}-\mathrm{PC}$ tablets should be controlled by adjusting the $\mathrm{Ca}^{2+}$ concentration in $\mathrm{Ca}-\mathrm{PC}$.

\section{Conclusions}

Since a sustained release tablet seems advantageous for the treatment of chronic inflammation in the oral cavity, preparation characteristics of B-LF tablets containing various types of pectin were investigated. From the release test, sustained release of B-LF was observed as the degree of esterification of the pectin increased. From the regression analysis, a possibility for prediction of the time required to release $50 \%$ of B-LF $\left(Y_{2}\right)$ by using the equation given by the degree of esterification $\left(X_{1}\right)$ and the logarithm of the molecular weight $\left(X_{2}\right)$ was suggested. Bioadhesive force of B-LF tablets tended to increase with increasing degree of esterification. However, prediction of the bioadhesive force $\left(Y_{1}\right)$ by using the equation given by $X_{1}$ and $X_{2}$ was not successful. As an explanation for this, the large variation in the data was considered. The B-LF release from the tablets containing $\mathrm{Ca}-\mathrm{PC}$ became prolonged as the amount of the $\mathrm{Ca}^{2+}$ addition to pectin $\mathrm{D}$ increased. The bioadhesive force of the Ca-PC tablets tended to increase as compared with the pectin D tablets. From the results, it is suggested that pectin with a high degree of the esterification is suitable as a bioadhesive polymer because high bioadhesive force and sustained release are observed. In the tablets containing Ca-PC, a possibility that the B-LF release from the tablets is controlled by adjusting the amount of $\mathrm{Ca}^{2+}$ addition to pectin is shown.

Acknowledgements This work was supported by the Ministry of Education, Culture, Sports, Science, and Technology of Japan. We appreciate the experimental assistance of Ms. Rie Iwaoka and Ms. Junko Suzuki.

\section{References}

1) Sato R., Inanami O., Tanaka Y., Takase M., Naito Y., Am. J. Vet. Res., 57, 1443-1446 (1996).

2) Duncan M., Grant G., Aliment. Pharmacol. Ther., 18, 853-874 (2003).

3) Masson P. L., Heremans J. F., Comp. Biochem. Physiol. B., 39, 119 129 (1971).

4) Pentecost B. T., Teng C. T., J. Biol. Chem., 262, 10134-10139 (1987).

5) Yu L. C., Chen Y. H., Biochem. J., 296, 107-111 (1993).

6) Masson P. L., Heremans J. F., Schonne E., J. Exp. Med., 130, 643658 (1969).

7) Arnold R. R., Cole M. F., McGhee J. R., Science., 197, 263-265 (1977).

8) Bullen J. J., Rogers H. J., Griffiths E., Curr. Top. Microbiol. Immunol., 80, 1-35 (1978).

9) Arnold R. R., Brewer M., Gauthier J. J., Infect. Immun., 28, 893-898 (1980).

10) Cumberbatch M., Dearman R. J., Uribe-Luna S., Headon D. R., Ward P. P., Conneely O. M., Kimber I., Immunology, 100, 21-28 (2000).

11) Catoire L., Goldberg R., Pierron M., Morvan C., Herve du Penhoat C., Eur. Biophys. J., 27, 127-136 (1998).

12) Fishman M. L., Chau H. K., Hoagland P., Ayyad K., Carbohydr. Res., 323, 126-138 (2000).

13) Manabe T., "Pectin", Saiwai Shobo, Tokyo, 2001, pp. $8-10,87,91$, 95.

14) Ralet M. C., Dronnet V., Buchholt H. C., Thibault J. F., Carbohydr Res., 336, 117-125 (2001).

15) Garnier C., Axelos M. A. V., Thibault J. F., Carbohydr. Res., 256, 7181 (1994)

16) Lofgren C., Guillotin S., Evenbratt H., Schols H., Hermansson A. M., Biomacromolecules, 6, 646-652 (2005).

17) Siew C. K., Williams P. A., Young N. W., Biomacromolecules, 6, $963-969$ (2005)

18) Itoh K., Kubo W., Fujiwara M., Hirayama T., Miyazaki S., Dairaku M., Togashi M., Mikami R., Attwood D., Int. J. Pharm., 312, 37-42 (2006).

19) Fell J. T., Newton J. M., J. Pharm. Sci., 59, 688-691 (1970).

20) Nakamura F., Ohta R., Machida Y., Nagai T., Int. J. Pharm., 134, 173-181 (1996).

21) Ishida M., Machida Y., Nambu N., Nagai T., Chem. Pharm. Bull., 29, $810-816$ (1981).

22) Takayama K., Nagai T., Int. J. Pharm., 74, 115-126 (1991).

23) Takahashi Y., Iwata M., Machida Y., Jpn. J. Pharm. Health Care Sci., 28, 68-73 (2002).

24) Edsman K., Hagerstrom H., J. Pharm. Pharmacol., 57, 3-22 (2005). 